http://jmscr.igmpublication.org/home/ ISSN (e)-2347-176x ISSN (p) 2455-0450 crossref DOI: https://dx.doi.org/10.18535/jmscr/v7i10.07

\title{
Association of Matrix metalloproteinases with Essential Hypertension- A Case control study
}

Authors

\section{Dr R. S. Hermes ${ }^{1}$, Dr Santhi Silambanan², Dr B. Sendil Kumar ${ }^{3}$}

${ }^{1}$ Associate Professor, Department of Biochemistry, FAHS, Aarupadai Veedu Medical College \& Hospitals, Puducherry

${ }^{2}$ Professor, Department of Biochemistry, Sri Ramachandra Medical College \& Research Institute, Porur, Chennai

${ }^{3}$ Dean \& Director, FAHS, Vinayaka Mission's, Salem

\begin{abstract}
Background: Matrix metalloproteinase 9 (MMP-9), also known as 92 kDa type IV collagenase, 92 kDa gelatinase or gelatinase $B$ (GELB), is a matrix in, a class of enzymes that belong to the zinc metalloproteinases family involved in the degradation of the extracellular matrix. Gelatinase B or 92 kDa type IV collagenase, also known as matrix metalloproteinase-9 (MMP-9) plays an important role in the pathogenesis of hypertension. The present study was designed to evaluate whether fasting homocysteine is associated with essential hypertension by causing alterations in the endothelial biomarkers.

Methods: A total of 525 subjects between the age group of 20-55 years of age, from both sexes who were attending the Hypertensive clinic in Sri Ramachandra Medical College were enrolled for the study. They were grouped as three-Group I being controls, Group II hypertensives without omorbities and Group III hypertensive with end organ damage. After overnight fasting, blood and spoturine samples were collected. All the biochemical parameters were estimated by standard methodologies. The plasmahomocysteine was determined by ELISA method (Axis Shield, UK), MMP-9 was determined by ELISA Method (R\&D SYSTEMS, Minneapolis, USA)

Results: The results are expressed as Mean $\pm S D$. The MMP-9 mean levels were found to be $100 \pm 99$, $155 \pm 29$ and $219 \pm 27$ (in $\mathrm{pg} / \mathrm{mL}$ ) in groups I, II and III respectively.

Conclusion: The activation of these MMPs may be generated by vascular cell adhesion protein (VCAM1) and intercellular adhesion molecule (ICAM-1) being up regulated in hyperhomocysteinemia leading to increased monocyte and leukocyte binding

Keywords: Essential hypertension, mmp-9, homocysteine, extracellular matrix.
\end{abstract}

\section{Introduction}

Elevated homocysteine is known to increase oxidative stress that causes oxidative injury to the vascular endothelium, diminishes vasodilatation by nitric oxide, stimulates the proliferation of vascular smooth muscle cells, and alters the elastic properties of the vascular wall. All these are associated with the rise in hypertension. Thus, homocysteine may contribute to blood pressure elevation. Proteins of the matrix 
metalloproteinase (MMP) family are involved in the breakdown of extracellular matrix in normal physiological processes, such as embryonic development, reproduction, angiogenesis, bone development, wound healing, cell migration, learning and memory, as well as in pathological processes, such as arthritis, intracerebral hemorrhage, ${ }^{[1]}$ and metastasis ${ }^{[2]}$. Most MMPs are secreted as inactive pro proteins' which are activated when cleaved by extracellular proteinases. The enzyme encoded by this gene degrades type IV and V collagens and other extracellular matrix proteins ${ }^{[3]}$.

Within the endothelial extracellular matrix two MMPs are of importance; these are MMP-2 and MMP-9. The reason that these two MMPs are of high importance is because they are the only ones capable of degrading collagen type IV and are classified as gelatanases. This interaction with collagen is especially important in capillaries and microvessels related to neuron microvascular health. In hyperhomocysteinemia these two MMPs have been shown to interact with endothelial tight junction proteins in capillary settings and increase permeability and leakage ${ }^{[4]}$.
In events where these proteases are overly activated there is a marked decrease in vascular wall integrity ${ }^{[5]}$.

\section{Materials \& Methods}

It was a hospital based case control study involving patients attending hypertension clinic of Sri Ramachandra Medical College \& Research Institute. Both the sexes in the age group of 20-55 years were included for the study.

This study is of its first kind involving three groups - Group I being controls, Group II being hypertensives without end organ damage, Group III being hypertensives with clinical or laboratory evidence of end organ damage. Based on the ECG, ECHO changes, fundus examination microalbumin levels in the urine the hypertensives were categorized into Group II and III.

530 samples were collected out of which those meeting our inclusion and exclusion criteria were included. The number was 175 in each of the three groups. The plasma homocysteine was determined by ELISA method (Axis Shield, UK), MMP-9 was determined by ELISA Method (R\&D SYSTEMS Minneapolis, USA)

\section{Results}

Table 1.0 Demographic data and Dietary Pattern of the 3 groups

\begin{tabular}{|l|c|c|c|c|}
\hline S.No & Parameters & Group-I $(\mathbf{n = 1 7 5})$ & Group-II $(\mathbf{n = 1 7 5})$ & Group-III $(\mathbf{n = 1 7 5})$ \\
\hline 1. & Age & $40 \pm 10$ & $49 \pm 8$ & $48 \pm 7$ \\
\hline 2. & Sex male & 49 & 71 & 89 \\
& Female & 126 & 104 & 86 \\
\hline 3. & Veg / nonveg & $24 / 151$ & $38 / 137$ & $34 / 141$ \\
\hline 4. & Smoking & $14 / 49$ & $23 / 71$ & $38 / 89$ \\
\hline 5. & Alcohol & $11 / 49$ & $25 / 71$ & 118 \\
\hline 6. & $\begin{array}{c}\text { Coffee } \\
\text { consumption }\end{array}$ & 139 & 121 & \\
\hline
\end{tabular}

Table 2.0 Clinical and Physical characteristics of the 3 groups

\begin{tabular}{|c|c|c|c|c|c|}
\hline S.No & Parameters & Group-I $(n=175)$ & Group-II (n=175) & Group-III(n=175) & P value \\
\hline 1. & $\mathrm{SBP}(\mathrm{mm} \mathrm{Hg})$ & $114 \pm 9$ & $136 \pm 15$ & $141 \pm 16$ & $<0.0001$ \\
\hline 2. & $\mathrm{DBP}(\mathrm{mm} \mathrm{Hg})$ & $77 \pm 6$ & $88 \pm 11$ & $90 \pm 9$ & $<0.0001$ \\
\hline 3. & BMI & $23.6 \pm 3.4$ & $24.1 \pm 3.38$ & $25 \pm 3.39$ & $<0.0001$ \\
\hline 4. & $\begin{array}{c}\text { Waist / Hip } \\
\text { Ratio }\end{array}$ & $0.87 \pm 0.08$ & $0.89 \pm 0.08$ & $0.90 \pm 0.05$ & 0.001 \\
\hline
\end{tabular}


Table 3.0 Tukey -HSD Post-hoc test results of SBP, DBP, BMI and WHR

\begin{tabular}{|l|c|c|c|c|}
\hline S.No & Parameters & $\begin{array}{c}\text { Group I \& II } \\
(\mathbf{n = 1 7 5 , 1 7 5}) \\
\text { P value }\end{array}$ & $\begin{array}{c}\text { Group II \& III } \\
(\mathbf{n = 1 7 5 , ~ 1 7 5 ~}) \\
\text { P value }\end{array}$ & $\begin{array}{c}\text { Group I \& III } \\
(\mathbf{n = 1 7 5 , 1 ~ 7 5 ~}) \\
\text { P value }\end{array}$ \\
\hline 1. & SBP $(\mathrm{mmHg})$ & $<0.001 * *$ & $0.035 *$ & $<0.001 * *$ \\
\hline 2. & DBP $(\mathrm{mmHg})$ & $<0.001 * *$ & 0.057 & $<0.001 * *$ \\
\hline 3. & BMI $\left(\mathrm{kg} / \mathrm{m}^{2}\right)$ & 0.307 & 0.482 & $0.022 *$ \\
\hline 4. & Waist / Hip ratio & 0.039 & 0.846 & $0.008 *$ \\
\hline
\end{tabular}

$* \mathrm{P}$ value $<0.05$ is considered statistically significant.

**P value $<0.001$ is considered statistically highly significant

Data are expressed as mean \pm SD. Comparing the mean values a statistically significant difference ( $\mathrm{p}$ value <0.05) was observed in BMI and Waist/Hip ratio among the 3 groups while SBP and DBP showed a statistically high significant difference indicating that blood pressure raises as the disease progresses.

Table 4.0 Levels of endothelial biomarkers in the three groups

\begin{tabular}{|l|c|c|c|c|c|}
\hline S.No & Parameters & Group-I $(\mathbf{n = 1 7 5})$ & Group-II $(\mathbf{n = 1 7 5})$ & Group-III $(\mathbf{n = 1 7 5})$ & P value \\
\hline 1. & Homocysteine $(\mu \mathrm{mol} / \mathrm{L})$ & $20.2 \pm 13$ & $28.2 \pm 13$ & $43.7 \pm 14$ & $<0.0001^{* *}$ \\
\hline 2. & MMP-9 $(\mathrm{pg} / \mathrm{mL})$ & $100 \pm 22$ & $155 \pm 29$ & $219 \pm 27$ & $<0.0001^{* *}$ \\
\hline
\end{tabular}

$* \mathrm{P}$ value $<0.05$ is considered statistically significant.

$* * \mathrm{P}$ value $<0.0001$ is considered statistically highly significant

Table 5.0 Association of endothelial biomarkers with end organ damage in essential hypertensives

\begin{tabular}{|l|c|c|c|c|}
\hline S.No & Risk factor & Odds Ratio & $\mathbf{9 5} \%$ CI & P value \\
\hline 1. & eNOS $(\mathrm{pg} / \mathrm{mL})$ & 9.8 & $1.5-209$ & 0.0247 \\
\hline $3 .$. & ICAM-1 $(\mathrm{pg} / \mathrm{mL})$ & 6.4 & $3.1-31.7$ & $<0.0001 * *$ \\
\hline $4 .$. & VCAM-1 $(\mathrm{pg} / \mathrm{mL})$ & 2.64 & $1.53-4.62$ & $<0.0001 * *$ \\
\hline $5 .$. & MMP-9 $(\mathrm{pg} / \mathrm{mL})$ & 46 & $24.2-88.6$ & $<0.0001 * *$ \\
**P value $<0.0001$ is considered statistically highly significant
\end{tabular}

\section{Discussion}

Essential hypertension remains a major modifiable risk factor for cardiovascular disease (CVD) despite important advances in our understanding of its pathophysiology and the availability of effective treatment strategies. High blood pressure (BP) increases the risk of CVD for millions of people worldwide, and there is evidence that the problem is only getting worse. In the past decade, age-adjusted rates of stroke incidence have risen, and the slope of the age-adjusted rate of decline in coronary disease has leveled off. The incidence of end-stage renal disease and the prevalence of heart failure have also increased. A major contributor to these trends is inadequate control of BP in the hypertensive population.

The demographic data and Dietary pattern of the 3 study groups are represented in Table 1.0.
The mean age was found to be $40 \pm 10,49 \pm 8$ and $48 \pm 7$ in groups I, II and III respectively. The age did not show much difference between group II and III. Among the study population, females contributed a greater part when compared with the males. There is almost an equal distribution of males $(n=89)$ and females $(n=86)$ in group III. The number of males was 49,71 in group II and III respectively. The number of females was 126, 104 in group II \& III respectively. In groups I and II there is a female preponderance.

Regarding the dietary pattern, it was observed that in group I, 24 were vegetarians while the remaining 151 were non-vegetarians. In group II, 38 were vegetarians and 137 were non vegetarians. In group III, 34 were vegetarians and 141 were non vegetarians. Thus the ratio of vegetarian to non-vegetarian participants in the groups ranges from 1:3 to 1:6. 
Since coffee consumption is one of the secondary causes for hyperhomocysteinemia the questionnaires also include the coffee consumption status of the individuals included in this study. It was found that in group I $(n=139)$, group II $(n=121)$ group III $(n=118)$ consumed coffee less than nine cups per day. It was thus observed that almost $80 \%$ of the study population consumed coffee in all the three groups. Caffeine plays a role in homocysteine metabolism thus it has an effect on homocysteine levels in essential hypertensives.

In group I, 14 were smokers, group II, 29 and in group III, 38 were smokers among the males. The ratio of smokers observed in the three groups was $1: 2$ to $1: 3$, with almost $50 \%$ in group III, indicating that smoking also contributes to end organ damage in essential hypertensives. Smoking exacerbates the effects of homocysteine in that it also acts independently from other vascular risk factors.

In groups I, II and III among the males 11, 25 and 30 individuals were alcoholics 1,2 and 3 respectively. The distribution of alcoholics as observed in the table ranges from 1:3 to 1:4.

The clinical and physical characteristics are represented in Table 2.0. Data is expressed as mean \pm SD. The mean values of Systolic blood pressure was found to be $114 \pm 9,136 \pm 15$ and $141 \pm 16$ in groups I, II and III respectively. The mean levels of diastolic blood pressure was observed as $77 \pm 6,88 \pm 11$ and $90 \pm 9$ in groups I, II and III respectively. The mean level of both systolic and diastolic blood pressure was found to be higher in hypertensives with end organ damage when compared with controls as well as hypertensives without end organ damage. The mean BMI was found to be $23.6 \pm 3.4,24.1 \pm 3.38$ and $25 \pm 3.39$ in groups I, II and III respectively. Comparing the mean values a statistically significant difference ( $\mathrm{p}$ value $<0.05)$ was observed in BMI and Waist/Hip ratio among the 3 groups while SBP and DBP showed a statistically highly significant difference indicating that blood pressure raises as the disease progresses.
Since a statistical difference was observed Tukey post-hoc Bonferrni test was done to identify the difference between the three groups as shown in Table 3.0. Between the groups I \& II a highly statistical difference was observed in SBP and DBP. Hypertension sets in even before the hypertensives go in for end organ damage as shown by the significant difference between groups I and II $(\mathrm{P}<0.0001)$ with minimal or no significant difference between groups II and III in the other parameters.

When control group was compared with hypertensives with end organ damage a statistically significant difference was observed in BMI and WHR $(\mathrm{p}<0.05)$. A significant change occurs in BMI and WHR when hypertensives developed end organ damage as shown by the statistically significant difference between groups I and III ( $\mathrm{p}=0.022)$ and $(\mathrm{p}=0.008)$ for WHR. It is obvious that BMI and WHR play a significant role in development of end organ damage in essential hypertensives. A highly statistically significant difference $(p<0.001)$ was observed in SBP and DBP.

SBP showed a statistically significant difference $(p<0.05)$ when hypertensives without end organ damage were compared with hypertensives with end organ damage while the other parameters did not show any statistically significant difference between the two groups.

The matrix metalloproteinases play an important role in altering the collagen/elastin ratio. The MMP-9 mean levels were found to be $100 \pm 99$, $155 \pm 29$ and $219 \pm 27$ (in $\mathrm{pg} / \mathrm{mL}$ ) in groups I,II and III respectively. Table 4.0

Derosa et al. ${ }^{[6]}$ measured MMP-2, MMP-9 and TIMP -1 enzyme levels in plasma samples of patients with hypertension. They reported that MMP-2 and MP-9 enzyme levels were determined high in hypertensive patients. They reported that these parameters may be a clinical marker. Yasmin et al. ${ }^{[7]}$ have reported that patients with systolic hypertension and aortic stiffnees have increased MMP-2 and MMP-9 enzyme activity. 
Some researchers reported that MMP-9 levels are higher in hypertensive patients than in normotensive controls ${ }^{[7,8]}$. Supporting the above studies the mean levels of MMP-9 was (100 \pm $22,155 \pm 29,219 \pm 27$ ) in the 3 groups.

Odds ratios (ORs) and 95\% confidence intervals (CIs) were calculated to evaluate the strength of the associations of endothelial biomarkers in assessing end organ damage Table 5.0. The odds ratio was found to be maximum for MMP-9 $(\mathrm{OR}=46)$

Hypertensive patients express higher levels of MMP-9 in serum, which positively correlate with aortic stiffness, contributing to collagen breakdown and arterial dispensability. An increase in fibrillar collagen in the compensated stage of hypertension is associated with increased MMP-9 activity ${ }^{[9]}$. MMP-9 activity is increased in arteries with high pressure compared with vessels under normal pressure ${ }^{[10]}$. Compensatory cardiac hypertrophy that develops in response to an increased pressure overload in hypertension is an established risk factor for atrial fibrillation, diastolic and systolic heart failure (HF), and sudden death $^{[11]}$.

Compensatory hypertrophy of the heart is associated with increased MMP-9 activity. Li et al. showed increased MMP-9 activity during compensatory hypertrophy in spontaneously hypertensive rats ${ }^{[12]}$. ECM degradation increases during the transition stage from compensation to clinically apparent $\mathrm{HF}$ and associates with increased MMP-9 activity ${ }^{[13]}$.

\section{Conclusion}

There is some evidence supporting a hypothesis of MMP activation besides just saying, "reactive oxidative species activate MMPs," which is a common phrase in oxidative studies of hyperhomocysteinemia. The activation of these MMPs may be generated by vascular cell adhesion protein (VCAM-1) and intercellular adhesion molecule (ICAM-1) being upregulated in hyperhomocysteinemia leading to increased monocyte and leukocyte binding ${ }^{[14,15]}$

\section{Acknowledgement}

This work was supported by Founder-Chancellor Research Fellowship, Sri Ramachandra University, Porur, Chennai -India,

I acknowledge the support rendered by Dr. B. Sendil Kumar, Dean \& Director, FAHS, Vinayaka Mission's, Salem

Conflicts of interest: None.

\section{References}

1. Wang J, Tsirka SE. "Neuroprotection by inhibition of matrix metalloproteinases in a mouse model of intracerebral haemorrhage." Brain. 2005;128 (7): 162233.

2. Van; Vandooren, J; den Steen, PE; Opdenakker, G.. "Biochemistry and molecular biology of gelatinase $\mathrm{B}$ or matrix metalloproteinase-9 (MMP-9) The next decade". Crit Rev Biochem Mol Biol.2013;48 (3): 222-72.

3. Van; den Steen, PE; Dubois, B; Nelissen, I; Rudd, PM; Dwek, RA; Opdenakker, G. "Biochemistry and molecular biology of gelatinase B or matrix metalloproteinase-9 (MMP-9)". Crit Rev Biochem Mol Biol. 2002;37 (6): 375-536.

4. Genersch, E., Hayess, K., Neuenfeld, Y.,and Haller, H.Sustained ERK Phosphorylation is Necessary but not sufficient for MMP-9 Regulation in Endothelial Cells. J. Cell Sci. 2000;113: 4319-330.

5. Whatling $\mathrm{C}$, McPheat $\mathrm{W}$, Hurt-Camejo E.Matrix Management. Assigning Different Roles for MMP-2 and MMP-9 in Vascular Remodeling. Arterioscler Thromb VascBiol. 2004;24:10-11.

6. Derosa G., D'Angelo A., Ciccarelli L. Matrix Metalloproteinase-2, -9, and Tissue Inhibitor of Metalloproteinase-1 in Patients with Hypertension. Endothelium. 2006;13:227-31.

7. Yasmin Wallace S., Mceniery C.M., Dakham, Z. Matrix Metalloproteinase-9 ( 
MMP-9), MMP-2, and Serum Elastase Activity are Associated with Systolic Hypertension and Arterial Stiffness. Arterioscler Thromb Vasc Biol. 2005;25:372-78.

8. Tayebjee M.H., Nadar S.K., Mac Fadyen R.J. Tissue inhibitor of MMP-1 and MMP9 levels in patients with hypertension. Relationship to tissue Doppler indices of diastolic relaxation. AJH. 2004; 17 :77074.

9. Weber KT, Pick R, Jalil JE, Janicki JS, Carroll EP. Patterns of myocardial fibrosis. J Mol Cell Cardiol. 1989;21 (5):121-31.

10. Lehoux S, Lemarie CA, Esposito B, Lijnen HR, Tedgui A. Pressure-induced matrix metalloproteinase-9 contributes to early hypertensive remodeling. Circulation. 2004;109:1041-47.

11. Katholi RE, Couri DM. Left ventricular hypertrophy: major risk factor in patients with hypertension: update and practical clinical applications. Intl J Hypertens. 2011; 495349 .

12. Li H, Simon H, Bocan TM, Peterson JT. MMP/TIMP expression in spontaneously hypertensive heart failure rats: the effect of ACE- and MMP inhibition. Cardiovasc Res.2000; 46: 298-306.

13. Ahmed SH, Clark LL, Pennington WR, Webb CS, Bonnema DD, Leonardi AH, et al. Matrix metalloproteinases/tissue inhibitors of metalloproteinases: relationship between changes in proteolytic determinants of matrix composition and structural, functional, and clinical manifestations of hypertensive heart disease. Circulation. 2006;113: 2089-96.
14. Silverman MD, Ramapogal JT, Davis M, Lopez G, Rosenbaum JT, Lelkes PI. Homocysteine Upregulates Vascular Cell Adhesion Molecule1 Expression in Cultured Human Aortic Endothelial Cells and Enhances Monocyte Adhesion. Arteriosclerosis Thromb Vasc Biol. 2002;22:587-92.

15. Deem TL, Cook-Mills JM.Vascular Cell Adhesion Molecule-1 (VCAM-1) Activation of Endothelial Cell Matrix Metalloproteinases. Blood. 2004; 104: 2385-393. 